\title{
Efficient Education Environment at University Level
}

\author{
A. Selmeci, T. Orosz \\ Obuda University, Alba Regia University Centre \\ Budai út 45, H-8000 Székesfehérvár, Hungary \\ e-mail: selmeci.attila@arek.uni-obuda.hu; orosz.tamas@arek.uni-obuda.hu
}

Abstract: Technology changes in the last twenty years accelerated and speeded up the life around the World. Nowadays new generations arise having no paper based textual information, technology based and thinking young people are coming to the universities in the next years. The universities and the education systems are currently not prepared to handle the different thinking, living, learning mechanism of them. Our study highlights the possible problems and show a way how to cover in short time the gap and offers new directions as well.

Keywords: education, e-learning, enterprise resource planning, efficiency, generation change

\section{Introduction}

The ability to teach and educate people in an efficient way is depending not only on the well-trained teacher and the availability of equipment (e.g. in experimental physic) nowadays. The master should be regularly trained, retrained, and brought nearer to the IT world. The education should be supported by means of new technologies, web based sources and other special tools. The generations coming to the universities represent new era and the education should follow them or in better case show the right way.

The universities educate not only young students, but also several people coming from other generation, having different behavior, learning habits. So the university should offer diversity in education forms, methodologies and techniques. To manage it some technological enhancement and aid tool should be implemented and applied.

In the following sections we go through the different generations and their problems and requirements, we show the tools available and usable for educating new generations, and the place of this software in the university environment.

\section{Generation and cultural gap}

We all heard, know and say many times, that it was different in my ages. It was true, it is true, and it will be true at any time because the World, the people are changing. But we can now realize that the time periods are shorter and shorten between changes. From 
technical point of view the television was introduced in (almost) every flat, we have recognized that computers can be small and at home we can use them for many purposes, we have learned the Internet boom, we have cell phones, day by day we use home entertainment equipment (audio, video, games, etc.). If we look back all these changes were made within a short century. If we try to buy a cell phone today, we do not think about a phone anymore, but a small computer having its own operating system and color display, which is better than the standard television. We did not recognize step by step the changes, but many daily used tools today have their own computers and the people went far away from the tool itself. For example ten or more years ago the mechanic could repair the car or wash machine, but today the computer of the car should be checked first, or the electronic panel of the wash machine should be changed (not repaired!) as a unit. The daily used tools are so complex and specialized, that nobody can learn alone the whole structure, architecture of them. Much more information, practice and special knowledge are needed to manage them, than a single person can achieve.

In psychology and demography studies we can read about new generations. As we show with natural examples above the changes are constant, but accelerated. The generations follow the changes, because the little child who lives with grandparents and every minute someone reads a textbook to him brings not only different relationship to books, reading, than others who immediately have got a pad to play. The small computers, games, videos are nowadays in the families; the small children learn how to use them immediately. Different demography generations still active or learning:

- 1920-1945 - Builders: After the World War I the main event in this period was the Great Depression, which generated efficient individuals in learning and working using cost conscious living.

- 1946-1964 - The Baby Boomer: As the name says this generation is very large, started after the World War II. Natural rebuilding of population. (Mainly in US.) In Europe the communism changed the thinking, generated collaboration, underground organizations and mistrust in anyone. Governmental control predefined how, what to learn and closed the communication, information flow and progression achieved by the non-communist states. (This modified the behavior of the adults (older generation), but influenced the children of this generation as well.)

- 1965-1980 - Generation X: This generation is smaller than the previous one (in US, but in communist states a small growth can be recognized). These people are independent, hardworking persons, but skepticism and liberalism are in focus as well originating from the semi-stabile living environment.

- 1981-1999 - Generation Y: Seeing the years of the period, we realize the starting ear of home computers. The children in this generation faced early with technology and electro-mechanical tools. They live with them, so they are confident if not even always brave enough. The members of this generation are technologically advanced, because they did not learn, but use the tools immediately as standard parts of the life. They are sometimes unrealistic, fighting, and demanding. They try to be connected technically, but they are lonely. 
- 2000-2009 - Generation Z: This generation has received little attention in the literature thus far, but they do not know how to live without Internet. They act instantly and they are available every time, but unscheduled. If they have no access, they are upset and cannot find their way for a period of time. This generation shares everything, more than having sense. Everyone from this generation shares the knowledge, experiences and the others accept it without control. Anyone can be an expert. They believe in Internet, anyone with similar or less skills can be better source of information than the living persons from older generation. Not too much self-knowledge, rather common, „crowd” knowledge is accepted. They cannot focus on one single topic, they are multitasking all the time, even they are face-to-face with others. Less unorganized, unstructured gaming is available, because they are connected vie a device and they cannot leave it for the time of playing with others. This leads to less conflict resolution skills or even face-to-face communication problems.

- 2010-present - Generation Alpha: This generation is very young currently and we do not know too much about their characteristic. The beginning of this (and the previous one) generation is not really definite. The members are those children, whose life is completely digital, living in Internet as child, having iPad as teddy bear. A child born earlier in 21 th century, but digitally infected, can be considered as member of the generation.

If we just look back, our universities are facing with the Generation $\mathrm{Y}$ persons nowadays, but in a few years the Generation $\mathrm{Z}$ comes to the institutes with a fundamentally different behavior, thinking, learning mechanism, interest and basic knowledge. So the main focus is the last two generations, because the currently reigning educational system cannot handle these generations and their behavior.

The earlier student grew up as empty sheet of paper, which should be filled up with the knowledge available. Mainly lexical knowledge, and some coherency and dependency build the information to be learned. On the other hand these information year by year throve with experiences and practice. The students learned how to solve a specific problem. In the life they could originate any solution in the learned examples or already experienced ones. New problems could be solved using the mixture of the already known techniques.

The new generations follow Einstein's sentence: "Never memorize something that you can look up." This can be good or enough if same basic, lexical knowledge is available as foundation, and the student has a good problem solving skill using the references he know. If they cannot see the correlation between the parts of a problem, or they cannot analyse and split it to smaller, easier pieces, they can quickly loose. New learning methods and tools should be provided soon to help them to find the right way in learning.

\section{Institute level trainings}

We have to realize that different types of students are around the institutes (e.g. universities). In the second section we have discussed the general, young university students' behavior, requisite and capabilities. But at each university the picture is much more colorful. 
Students are part of international student programs, evening course, correspondence course, doctoral school, adult education, etc.

As we described in the earlier sections the students are changing dramatically, especially at the standard day school. The older generations, building mainly the other, not standard day courses follow the old fashion, worked well models, techniques. With the new technology era, like smartphone or pads are at any students, portable computers are in the case, the teacher many times does not know what to do, how to keep the students away from their equipment during the classroom training. We can realize that when the teacher is closer to the generation of students, he can take the equipment more effectively part of the training. Not forbid, but use them.

But at the university not only they are the only students, but other level of education is taking place as well. Just as a short list we have here the other possible students:

- $\quad$ Full time course (older generation, currently educated)

- Correspondence (different generations could occur)

- Continuative education (e.g. for engineers)

- Doctoral school

- Postgraduate course (for teachers at the university, proficiency career)

As you can see, the different types of education target different learning groups, generations. We cannot say that each type has a well-defined, restricted age period, because except the case of regular full time course the others educate students, people from almost any age. But almost each of these types of students has already experience with the currently applied education system and they can accept it for further studies as well. Of course in most of the scientific areas (e.g. Bachelor of Arts, natural science, or even informatics) we have to follow the challenges standing for the education of the newest generation. The cause of that is laying in the changing of the whole World and daily life of the people. The Y, X or older generations learn and use day-by-day the potential offered by the new technology era and they require the changes as well.

The difference ages and the modified authority of a student (sometimes teacher) leave us to think about offering fuzzy education as well [1]. The nature of thinking is not changing so quickly, than the technology world around us. As in the referred paper you can read the student brings the uncertainty to the system.

The education at universities is nowadays like the basic commercialism, because the universities should follow the demand of the student with the supply or offerings. The next section goes a bit beyond.

\section{Education and e-learning}

Early 70s Ivan Illich publicized a reform theory about education [6]. The World immediately answered and from year to year this paper is referred and reflected because of its strong directions. 
From today's problems and availability we have to check it again with reference to education of Generation $Z$ and beyond. Before going deeper we have to see some thoughts of this theory. The reform education in his work liberate the students from following the well-defined, "engraved in stone" curriculum, but let them access to the sources of educational knowledge, which may help them to find their way to acquire knowledge.

The chapter "Learning Web" of Illich's paper defines four parallel living approaches, which

1. Reference Services to Educational Objects:

These could enable access to different learning elements, information sources and processes. The sources should be stored in an easy accessible manner for anyone. (Meaning scientific or manufacturing results, certificates, and authority control should be provided.)

2. Skill Exchanges:

Some forms and forums should be provided, where individuals can share their skills and the way, conditions how they reach them. This could serve as a model for the individual himself and for others in learning process.

3. Peer-Matching:

Cooperation or collaboration of equal parties in a communication network, where the individuals can find proper partners for their interest and learning goals.

4. Reference Services to Educators-at-Large:

Services should be provided enabling students to find the professional or nonprofessional educators, by searching their access, knowledge and skill descriptions, and conditions of consulting. The educators can be ranked and commented by the individuals, students.

If we look back to the second section of this paper, we can easily realize that the life, daily movements of the newest generation corresponds to the described offerings by Illich's idea. The listed approaches are almost enabled by the Web technologies and Internet. Just as short, but not complete listing of features offered by the today available Web elements we show here some practical enables of the approaches (these are global examples, not institute relevant ones):

1. Reference Services to Educational Objects:

Video (e.g. YouTube) or step-by-step tutorial of learning objects (offered by companies, institutions, etc.). Virtual, online museums (e.g. $\mathrm{http} / / /$ onlinetitanicmuseum.com/main/) or web gallery. Online book availability (e.g. http://www.readanybook.com/), e-books (e.g. http://books.google.com/), and voice books give online or offline availability of learning materials in written or read out form.

2. Skill Exchanges:

In information technology you can find the development networks (e.g. http://scn.sap.com/), or Open Source com-munities (e.g. http://www.apache.org/) as primary source of information. Other form is the Wiki.

3. Peer-Matching:

Forums and chat services for different products, themes, thoughts.

4. Reference Services to Educators-at-Large:

Currently for companies and employees there are some recruiting help functionality (e.g. http://www.linkedin.com/). Not all the prescribed requirements 
are fulfilled, but self-descriptions, skill lists can be provided and individuals could rank and probate others (using work experience).

As we see the new technology enabled many ideas from the 70s, and the new, Internet generations would like to live, learn according the approaches.

From institutional point of view it is not so easy just offer the services described and hope that everything will go in a right track. To handle and really benefit from the approaches described above, some control, mentoring, regular surveying, measuring and qualifications are necessary.

To manage these challenges an e-Learning or LMS (Learning Management System) would be useful. (According to our study we cannot say that this is the only and complete solution, but is seems to be necessary for the current and coming educational challenges.) In the market we can find many offerings from different vendors for different prices. The main ERP (like SAP) software companies offer solutions because trainings, and further education of employees are many times key point of interest to keep the company's common knowledge and bench in up-to-date level in daily competition. In general these learning solutions as ERP system extensions are mainly coupled with human capital management (or human resources) components. The human resource component manages not only the employee's administration (like name, address, bank information, salary, etc.) and organizational labeling (e.g. department, job, position), but it could prepare, record and follow events or qualifications as well. Events can be obligatory trainings, certification exams or any other organized or not organized business event. An event (or training) is handled in more levels and link with other objects. As an example we can define for the employees English lessons. To define events we use grouping hierarchies like in our example:

- Language trainings [groups level 1]

- English courses [groups level 2]

- English for beginners [type 1]

- English Intermediate [type 2]

- English Upper-Interim. [type 3]

- Business English [type 4]

The bulletin levels show the hierarchies of the groups and the different event types defined in a specific group. Of course each of the trainings (events) should be linked to resources, like room (or class), instructor (or educator), material, etc. The resources should be configured before assigning them. One understandable reason could be that the event planning contains not only the event publications, but the resource allocation as well, and the organizer should know how many trainees would take part, because corresponding training room should be allocated. So the capacity (and available equipment) should be known for each training room before allocating them to an event. Other property of resources is of course the cost. The trainer should be paid according to length of the training and the number of participants. This property is important for cost planning not only in human resources component, but in financial and controlling areas of the ERP application as well. 
The business events or trainings can or should be provided in a catalog, like at the universities. In the catalog two additional properties can be added: schedule and prescribe. There could be standard trainings regularly organized, or on request organized trainings as well. If training is required for a job or for everyone joining a company, it is mentioned in the catalog for each employee.

Another part of the integration with human capital management is the qualification management. At a company the jobs or positions could require some educational level, certificate. In the qualification management two important parts can be handled:

- qualification of an employee

- qualification(s) needed for a job or position.

To manage these information in an integrated way the event management should be linked to the qualification management. The qualification should be defined as level of knowledge, which can be linked to a specific training or some trainings, certificate. The completed training should be recorded not only in event management, but also as a new qualification. These could help within the company to find the right person for an internally new or vacancy position.

The connection between jobs, positions, trainings, qualifications are independent technically, so a graph can be drown from the connection list. It is a useful small enhancement if the jobs and/or the qualifications can be grouped, because less information should be stored by arranging the qualifications and jobs into (separate) hierarchies.

A learning management system manages these information if required and it offers not only the event management, but making, storing and playing of training materials. These e-Learning systems provide different types of learning materials, especially SCORM (Sharable Content Object Reference Model) compatible objects, but other electronically formed contents, like MS PowerPoint, MS Word, PDF, etc. formats are acceptable. The SCORM has about ten year's old history. It is used to define a standard form and protocol to create and play e-Learning content in a way, where the progress can be followed. This last part is very important because of the measurement of the progress and achieved level of knowledge. In connection with human capital management the linked learning management system can share information about the training progress of each participant. This leads cost and qualification controlling immediately.

As we described the event management can assign resources, like training room (class) to an event (training). This is important in case of a class-based training. There could be other kind of trainings, events as well. First of all we have to distinguish between synchronous and asynchronous education. Synchronous education supposes that the trainer and the student are available in the same time. According to the second and fourth sections it does not mean definitely that they are in the same place as well. If we are speaking about distance learning no classroom is required. On the other hand we can imagine that though this event does not require allocated classroom in a building, but communication line, bandwidth for sharing screen, camera output and voice should be provided, or made available, or in other words allocated to the course. We can go one step further to the asynchronous education, where the training is an offline or interactive 
material, which is available for a given period of time, but no physical or virtual classroom should be allocated. The learning management system has to deal with the problem of follow-up or tracking. If the training material could contain and handle progress information, like the SCORM compatible materials do, some authenticated synchronization needed to receive the offline progress centrally in the e-learning system.

Another important way of knowledge measurement is the testing. Testing means here web based questionnaire using different formats and mechanism. The learner should timeto-time measured. For that some basic questions should be answer:

- Did I understand the training content?

- Do I remember the important visual information?

- Do I understand the overall logic of the training content?

- Do I remember the important lexical learning?

- Can I apply the learning in practice?

The teacher's task is to formulate interesting questions effectively. In the following some typical and usable test scenarios are listed.

- Simple true/false questions

- Decision or multiple choice (according of the task definition only one or more answer could be accepted)

- One word answers (the answer is one word, but more correct answer could be accepted)

- One number answer (same, but a number, e.g. a result is in question)

- Match the answers to the questions etc.

This short list just summarizes the frequent types of tasks or questions. But sometimes we give opportunity to the student to a short text, e.g. an essay. To help the student answering the question some additional text or even image would be helpful.

It is advisable to configure the available time for the answer. In some cases it is better to set this limit for each question, but generally an overall time limit is given. The testing environment should provide rethink or later modification possibilities. The measurement can be done according to the achieved number of points, but the execution time can correct this value as well. In general case the test system does not give a sign for the work, but only percent of the performance and the teacher later can assign signs to the test results.

These are only a recommendation and some minimal requirement from the learning management system. To be able to integrate the solution to the central university student management system (or at a company to the qualification management) the results (and the progress) should be interfaced to the connected systems. Generally the testing is a synchronous process. If you want to execute it offline, a special offline tool should be provided which stores the progress and results securely without any violence. 
The testing or questioning phase in the education process where the fuzzy logic can play bigger role [3]. The learner activity is in the focus during this phase. But the decisions are not only interesting at this point, but during the education process the student can use his own or any available device to understand the learning content better. (Here we have to refer to the $3^{\text {rd }}$ section, where the teacher does not forbid the use of device, but let the student decide whether to use any. Another reference should be made as well to the next section, where the possible trainings are discussed.)

The e-Learning systems have further capabilities, like forums, chat (instant messaging), dashboard, and even wiki or glossary functions for collaborations. It makes possible to organize brainstorming. But not each of the learning management system offers features to store information about the masters; many times they cannot always get evaluation. At university we have to be careful with this "Reference Services to Educators-at-Large" approach defined by Illich, because the people evaluating the educators are sometimes not really competent, or even have bad temper. This kind of unrealistic or bad natured comments, evaluations can destroy the life of a teacher, even hurt privacy lows. To handle this kind of issues moderator or group of moderators (committee) are needed. This is true for forums as well.

If we look back to the learning web approaches, we realize two interesting phenomenon:

- The approaches from $70 \mathrm{~s}$ almost cover the behavior and demand of the generation Z

- The e-learning systems almost cover technically Illich's approaches.

This figures out, that a change in the education at the university can be managed mainly with the help of a learning management system.

\section{Training possibilities}

As we described till now we have two main directions in Education:

- Traditional: class based, well-defined, structured, traceable, static

- e-Learning based: collaborative, self-defined, follow-up system, dynamic, digitally aided

Both have a place in education, but we have to go forward to follow the next generations to build well-educated persons from them as well. Some of the e-Learning systems can help us to enhance the classes and motivate the young generation.

According to our simple survey (not detailed in this paper) the students (generation Y) feel many times the standard lecture boring, while they are too slow. It does not mean that they are so fast and clever, but they live in a higher speed and the lectures are lack of activities, movements. The newer generations loose very quickly their interest if it is a bit slower than they're used to live. The interest goes to access others and communicate with them. This recognition led us to rethink e.g. the presentation style. The common presentation style is a linear progressing process with many textual enumerations, maybe some graphics enhance the content. If the presenter uses the prezi (https://prezi.com/), the 
presentation is not yet static having a linear path, but it extends to the possible connections (linked subject) as well. According to the progress, students' condition/combination and behaviour the educator can select what is important, what should be highlighted or hidden. The presenter should be much better prepared, because not an ordinary slide order is used, but he should "improvise" on the fly as occasion requires. This produce a more living presentation, which is closer to the new generations.

The e-Learning systems can help to manage lectures with more activities, because it supports many collaboration functionalities. In smaller groups the agile project management methodology could be used. It helps to keep the interest for the whole time of the lecture. The devices should be involved into the exercises. Fuzzy education can be another solution here.

The borders of this paper do not let us to detail further options available and applicable in such an environment, and other not e-Learning dependent techniques are neither discussed.

\section{Economical, cost efficient education}

Each of the universities has a unified study system (e.g. in Hungary Neptun or ETR). This kind of system manages the students' progress (semester, credit), the offered trainings, timetables, default curriculum, taken courses, exams, financial content (banking data, fee status, etc. The system handles not only the student view, but the teachers view as well. This is important because the teachers should define the course data, exam information, provide additional data, set the timetable, consultation occasions, record the results, etc. The system has simple collaboration functionalities, qualification information and dormitory management as well.

For cost efficiency an Open Source e-Learning system, the Moodle is advisable [4], because this has the offerings we described in previous sections for Enterprise use as well. The Moodle provides a lot of possibilities as standard, but with the development environment own functionalities can be added as well. As we described in the third section, the e-Learning system should handle offline Education as well. To fulfil this mechanism some extension should be used [5]. The Moodle offers the collaboration functionality to provide connectivity to the young generation and make possible to apply moderated and motivated trainings to bring the students taking part actively on the lesson.

As we mentioned an e-Learning environment can be used for qualification control and management as well, but in many cases these functions are out of scope. This is natural, because these functions belong to the ERP system. The previously mentioned unified study Systems define the Education management in the environment, the e-Learning provides the training contents and collaboration functionalities with the measurement, test scenarios. The unified study system collects the information and provides to the teacher, moderator, mentor or supervisor. The employees of the university, like the professors can be trained or continuative educated. The results can be stored as qualification, which is connected to the human capital management component of the ERP system. The ERP system manages the financial and controlling data as in connection with the unified study system, where the semester cost, dormitory cost, salary of the visceral educators and so on are coming from the study system. The ERP, unified study system and the e-Learning 
system can build an integrated whole. Before integrating the parties' performance and consistency simulation is recommended [2]. The self-defined Moodle extensions should be checked as well using the performance simulations.

\section{Summary}

In the paper we have collected the different type of student coming from different ages. As you have seen the new upcoming generations, and their behavior is totally different, than the currently living education systems with old fashion techniques can offer. Their requirements are very close to the Illich's web learning model, which can almost fulfilled with today's Internet and web technologies.

The e-Learning systems can build a bridge between the current and future education systems, but the feature sets are not enough, the teachers should be able to use these functionalities to pull out everything from the representatives of the new generation. They should motivate them to be active during the lectures as well, and the lessons should be animated and moderated, and the daily used devices (e.g. cell phones, laptops) should be involved not prohibited. Special education methods should be used, for testing and learning fuzzy education can help as well.

The e-Learning systems provides toolset to measure the learning effectiveness by testing, questioning. In the university environment the e-Learning system integrated to the ERP and unified study system, builds the main engine of the institute.

\section{References}

[1] Ösz, R., Fodor J.: Possible connecting areas of education and intelligent systems, IEEE 9th International Conference on Computational Cybernetics (ICCC), pp. 5156,2013

$$
\text { DOI: 10.1109/ICCCyb.2013.6617560 }
$$

[2] Muka, L., Benkö, B. K.: Meta-level performance management of simulation: The problem context retrieval approach, Periodica Polytechnica Electrical Engineering, vol. 55, no. 1-2 pp. 53-64, 2011

$$
\text { DOI: 10.3311/pp.ee.2011-1-2.06 }
$$

[3] Fodor, J., Ösz, R.: Possible applications of fuzzy methodology in the educational process, IEEE 11th International Symposium on Applied Machine Intelligence and Informatics (SAMI), pp. 37-40, 2013

DOI: 10.1109/SAMI.2013.6480992

[4] Shu-Ying. Li, Coll. Handan, Chao-Zheng. Yang, Yun. Hou: Study on enterprise training design of MOODLE, International Conference On Computer and Communication Technologies in Agriculture Engineering (CCTAE 2010), pp. 339341,2010

[5] Ngom, B., Guillermet, H., Niang, I.: Enhancing Moodle for offline learning in a degraded connectivity environment, International Computational Mechanics Symposium 2012 (ICMS2012), pp. 858-863, 2012

[6] Illich, I.: Deschooling Society, Harper and Row, New York, 1977 